\title{
ANTONINO PIO: ESTUDIO BIOGRÁFICO Y BIBLIOGRÁFICO DE UNA ÉPOCA
}

\author{
JOSÉ ANTONIO GARZÓN BLANCO
}

\begin{abstract}
En este artículo pretendemos analizar la obra del emperador romano del siglo II, Antonino Pio. No es nuestra intención entrar en un estudio pormenorizado de su vida, pues su biografía ya ha sido relatada por eminentes autores. Queremos reflejar el ambiente de una época, quizás la única del Imperio Romano, en que la gente, en términos generales, era feliz y se sentía feliz, un momento irrepetible y algo muy raro en la Historia de la Humanidad; así al menos lo interpreta el poeta de la época: Elio Arístides, a lo que hay que añadir el hecho de que fuese un período sin guerras, casi anodino, si no fuera por la gran cantidad de monumentos que nos han quedado de ese gobierno. Además de lo indicado, presentamos un amplio estudio bibliográfico de este período.

The second century A.C. has been called with every right «The Golden Age of the Antonines», indeed, during this century a unique class emerges in Universal History: That of philosopher emperors or friends of the Philosophers. Their activities during their mandates were always goberned by the principle of philosophical humanism. This is what we are trying to demostrate in this article.
\end{abstract}

T. Aelius Hadrianus Antoninus Pius, comenzó gobernando en la línea espiritual y política de su predecesor, Adriano. El largo reinado de Antonino Pio (murió en el año 161 a los setenta años de edad), fue el período más calmado y más «impersonal» de todo el Imperio. Su gobierno fue considerado por todos como el período supremo de apogeo del Imperio Romano, y el emperador mismo como el monarca ideal. Por esta razón es por lo que el epíteto de Pio ha quedado tradicionalmente vinculado a su nombre. A
Antonino Pio se le puede aplicar, casi mejor que a ningún otro emperador del siglo II d. de J.C., la frase que Tácito escribiese en el año 106 para referirse a este período: Rara Temporum Felicitas, (TACITUS, I, 1; S.H.A., Pius, XII, 4) cuando los hombres podían expresarse libremente, sin coacción alguna por el Estado. Por esta razón, se le considera junto con Adriano y Marco Aurelio, el mejor representante del «Imperio Liberal», que caracterizó el final del siglo I y buena parte del siglo II, desde Nerva a Marco Aurelio. 
Marco Aurelio expresa su admiración sin reservas por su antecesor en el trono, Antonino Pio, al dedicarle el capítulo más largo y detallado de «Mis Recuerdos» $\mathrm{o}$ «Meditaciones» (M. AURELIUS, I, 16; VI, 20). Antonino Pio, casado con Annia Faustina, hermana única del padre de Marco Aurelio fue, por tanto, tío político, padre adoptivo (desde el año 138) y suegro (desde el 145) de su sucesor, y antes colaborador asiduo en el trono imperial. Ningún otro es evocado en las Meditaciones con tanta extensión ni con un afecto tan enorme como Antonino Pio: «De mi padre»; la masendumbre y la firmeza serena en las decisiones profundamente examinadas. El no vanagloriarse de los honores aparentes; el amor al trabajo y la perseverancia; el estar dispuesto a escuchar a los que podían hacer una contribución útil a la comunidad. El distribuir sin vacilaciones a cada uno según su mérito. La experiencia para distinguir cuándo es necesario un esfuerzo sin desmayos y cuándo hay que relajarse. El saber poner fin a las relaciones amorosas con los adolescentes. La sociabilidad y el consentir a los amigos que no asistieran siempre a sus comidas y que no le acompañaran necesariamente a sus desplazamientos; antes bien, quienes les habian dejado momentáneamente por alguna necesidad le encontraban siempre igual. El examen minucioso de las deliberaciones y la tenacidad sin eludir la indagación, satisfecho de las primeras impresiones. El celo por conservar a los amigos, sin mostrar nunca disgusto ni loco apasionamiento. La autosuficiencia en todo y en la serenidad. La previsión desde lejos y la regulación previa de los detalles más insignificantes sin escenas trágicas. La represión de las aclamaciones y toda adulación dirigida a su persona. El velar constantemente por las necesidades del Imperio. La administración de los recursos públicos y la tolerancia ante la crítica en cualquiera de estas materias; ningún temor supersticioso respecto a los dioses ni disposición para captar el favor de los hombres mediante lisonjas o agasajos al pueblo; por el contrario, sobriedad en todo y firmeza, ausencia total de gustos vulgares y de deseo innovador. El uso de los bienes que contribuyen a una vida fácil, y que la Fortuna se los habia deparado en abundancia, sin orgullo y a la vez sin pretextos, de manera que los acogía con naturalidad, cuando los tenía, pero no sentia necesidad de ellos cuando le faltaban.

El hecho de que nadie hubiese podido tacharle de sofista, bufón o pedante; por el contrario, era nido por hombre maduro, completo, inaccesible a la adulación, capaz de estar al frente de asuntos propios y ajenos. Además el aprecio a quienes filosofan de verdad, sin ofender a los más ni dejarse tampoco embaucar por ellos; más todavía, su trato amable y buen humor, pero no en exceso. El cuidado moderado del propio cuerpo, no como quien ama la vida ni por coquetería»...

Para F. Millar «Nada muestra mejor el espiritu moderado y 'doméstico' del régimen de Antonino que este pasaje de las Meditaciones» (MILLAR, 1979, 43). Encontramos un contraste entre Adriano y Antonino, que incluso las notas de Marco Aurelio parecen evocar, tal vez, inconscientemente. Farquharson (GARCÍA GUAL 1977, 13), lo indica con claridad: «Su amor por las formas antiguas, su conservadurismo religioso se opone a la variabilidad y el capricho de Adriano, su economía pública y su frugalidad privada a la extravagancia de Adriano, su sencillez a la pasión de Adriano por las construcciones, los suntuosos banquetes y los jóvenes favoritos. Adriano era, además, envidioso e intolerante hacia sus rivales, aún con gente de gran talento, y la fantástica extravagancia de su suntuosa villa de Tívoli pudo haber desagradado a Marco Aurelio en contraste con las anticuadas villas campestres de Antonino Pio. Es evidente la diferencia entre el sencillo y práctico caballero campesino, y hombre genial desazonado, irritable a menudo, infeliz y enfermo Adriano». Antonino vivió dedicado por completo al Imperio, dentro de un círculo familiar sencillo y discreto, aspecto éste en el que se diferenció mucho de Adriano, cuyo matrimonio infecundo con Sabina que era hija Matidia, una sobrina de Trajano, acabó en separación; además tuvo escandalosas relaciones con un muchacho, Antinoo, que murió en extrañas circunstancias en el Nilo; nunca antes un emperador «razonable», había hecho el ridículo de semejante forma, y las repercusiones de este hecho se dejaron sentir a lo largo del Imperio durante años, fomentadas por el propio Adriano que construyó ciudades y acuñó monedas y medallas dedicadas al malogrado muchacho (BABELON-REINACH, 1925; BELL, 1940, 37-55; BLUM 1914, 37 70; DIETRICHSON, 1884; HAHLAND, 1954, 54 ss; KÜBLER, 1914; KUHN 1913; MARCONI, 1923, 161 ss; MATTINGLY 1931, 315; REINACH, 19041912; RIIS, 1945, 175 ss.; RIZZO, 1908, 3 ss; ROYSTON, 1983; SETLMAN, 1948; SYMONDS, 1883; 
SYMONDS, 1900; VOGT, 1924; WEBER, 1911). (En este sentido, Marco Aurelio quiso dejar al margen a su antecesor, Antonino, de relaciones con «los adolescentes», aunque algo de esto también debió haber, a juzgar por las palabras del propio Marco Aurelio relatadas más arriba).

Paradójicamente, Antonino tras su ascenso al trono mantuvo, por propia voluntad, la mayor parte de las decisiones políticas y actos realizados por Adriano; su honestidad personal le impedía cambiar las decisiones de aquel que le había hecho emperador, incluso en contra del parecer del Senado que, sumamente exasperado por las violencias que Adriano había seguido con muchos de sus componentes, se oponía con dureza a que éste recibiese el homenaje póstumo de la Apoteosis. Antonino se vio en la necesidad de amenazar con su dimisión si tal acto no se producía. «En este caso, dijo en su discurso al Senado, si él era un hombre inicuo y un enemigo público yo tampoco seré vuestro emperador. Pues si él era como decís anularéis sus disposiciones, una de las cuales era mi adopción» (S.H.A., Pius, IX, 10). De este modo, sin menoscabo alguno del poder imperial, Antonino decidió reconciliarse con el Senado, que, por lo demás, compartía sus mismos principios conservadores, lo cual le llevó a realizar una política totalmente acorde con esta Institución, siendo plenamente correspondido por la inmensa mayoría de los miembros del Senado. Su principal labor para con ellos fue la restitución del poder que Adriano les había arrebatado al devolverles la administración de los cuatro distritos en que Italia había sido dividida, eliminando con ello a los cónsules que con el rango de gobernadores respondían directamente ante el emperador. Por supuesto, ningún miembro del Senado fue condenado a muerte durante su gobierno.

El equilibrio mental de Antonino, casi inaudito en un emperador romano hasta esos momentos, unido a buenas dosis de sentido común y honestidad proporcionaron veintitres años de buen gobierno al Imperio. Muchos creyeron firmemente que estaban viviendo los mejores, e irrepetibles momentos, que nunca más volvería a tener Roma y las provincias del Imperio. A cambio, el gobierno romano sufrió un anquilosamiento en todas sus instituciones, fue un gobierno gris, sumamente pegado a las tradiciones, sin realce alguno que mereciese la atención de los historiadores y biógrafos. Los motivos de esto no deben buscarse tanto en los rasgos individuales del emperador como en la situación general internacional e interna. Las guerras sostenidas por Trajano, que eliminó, momentáneamente, a buena parte de los potenciales enemigos del Imperio, junto con el atrincheramiento tras los limites efectuado por Adriano, había traído una cierta estabilización en todos los órdenes, que Antonino no deseaba en nada modificar.

No obstante, la diversidad de temperamento y de las vicisitudes, el Imperio de Adriano, Antonino Pio y posteriormente Marco Aurelio tienen importantes rasgos comunes: «ellos son los emperadores fílósofos o amigos de los filósofos. Adriano inauguró un nuevo tipo de monarca, que conscientemente se llama Augusto y se contrapone a César. Adriano viajó mucho y Antonino poco o nada; pero la diversidad entre los emperadores queda atenuada por la presencia de la Virtus Filosófica en su ideal de vida. Otra diferencia entre Adriano y Antonino Pio es la trabajosa actividad edilicia de Adriano (trabajo que se remonta, como han demostrado ciertas excavaciones en Hungría en 1951, al período anterior a su ascensión al trono, en contra de la mesurada economía de Antonino Pio» (MAZZARINO, 1980, 325). No obstante, en los últimos años, se está viendo que, pese a la proverbial economía de Antonino, éste continuó y terminó la mayor parte de las obras que su antecesor no había acabado, como indica la Historia Augusta, «las Provincias prosperaron bajo su gobierno» (S.H.A., Pius, VII, 1). Esto se manifestó en la ampliación y reparación de la red de calzadas en todas las regiones del Imperio. En cuanto a la construcción de edificios públicos éstos fueron importantes, por ejemplo, en el norte de Africa, donde construyó o restauró los acueductos, las grandes cisternas que servían para la distribución de agua y termas de Cartago, los llamados «baños de Antonino» o los templos y arco de la ciudad de Sufetula, ambas en la actual Túnez; al parecer, el emperador quiso realizar en esta zona una importante labor de repoblamiento, embellecimiento y ampliación de las ciudades. También en Asia, donde en Aspendus, su teatro fue personalmente financiado por el emperador, construido por el arquitecto Zenome, los miliarios de la calzada que conduce al teatro informan que la calzada fue igualmente construida a expensas del emperador. No podemos dejar de mencionar en este sentido el magnífico templo construido en honor a su mujer Faustina en el Foro Romano, el templo de Antonino y Faustina, hoy día conservado al convertirse en iglesia cristiana. Dice la 
Historia Augusta que se hicieron empréstitos a numerosas ciudades para la realización de obras municipales y sobre sus construcciones en Roma afirma lo siguiente: «Subsisten todavía las siguientes obras públicas realizadas bajo su iniciativa: el templo de Adriano en Roma consagrado para honrar a su padre, el Grecoestadio restaurado después de haberse incendiado, el anfiteatro reconstruido de nuevo, el sepulcro de Adriano, el templo de Agripa, el puente Sublicio, el Faro restaurado, el puerto de Cayeta, la reforma del puerto de Terracina, los baños de Ostia, el acueducto de Ancio y los templos de Lanuvio» (HAGEN, 1973, 77; S.H.A., Pius, IV, 10; VI, 7; BARADEZ, 1935, 2432; BARADEZ, 1949; BERNABOU, 1976; BOISSIER, 1912; DI VITA, 1964, 65 ss; FREZOULS, 1980, 65-93; COMPARETE, 1976, 166-183; GOODCHILD, 1948; MATTINGLY, 1984; MERIGHI, 1940; NICHOLS, 1978; PICARD, 1959; REYNOLDS, 1978, 111 ss; ROMANELLI, 1959; SALAMA, 1950; SIGMAN, 1976; SYME, 1959, 310 ss; TISSOT, 1884-1988; WARD, 1952). La misma fuente nos informa que hubo grandes calamidades públicas durante su gobierno y que para paliarlas se necesitaron fuertes inversiones de la Hacienda Imperial. Así, dice que se produjeron grandes incendios, uno acaeció en la propia ciudad de Roma y destruyó trescientas cuarenta casas dejando sin techo a varios miles de habitantes. Otros también de gran importancia devastaron las ciudades de Narbona y Antioquía, además del Foro de Cartago. Los terremotos destruyeron varias ciudades de la isla de Rodas y de la Provincia de Asia, todas ellas mandadas reconstruir por Antonino. También se produjo un hundimiento parcial del Coliseo Romano y una inundación del Tiber (S.H.A., Pius, IX, 1-3).

El nuevo soberano, cuyos antepasados procedían de Nemausus, la actual Nimes, en la Provincia de la Galia Narbonense, había nacido en una importante familia burguesa que se había enriquecido con la industria de material de construcción, desde hacía dos generaciones pudieron inscribir sus nombres en las listas consulares, se habían distinguido en diversas magistraturas senatoriales sin haber jamás tenido el mando del ejército. Llegó al trono con una considerable fortuna, aumentada con el matrimonio con Faustina (FRAZE, 1960, 271-274; GIACOSA, 1969; HOWAT, 1928; LAFFRANCHI, 1937, 110-114; MATTINGLY, 1943, 147 ss; SLATER, 1967, 3 ss.), la cual también procedía de una familia acomodada. J. Carcopino y P. Grenade (CARCOPINO, 1949, 262-
321; GRENADE, 1950, 258-277) resaltan la continuidad de los vínculos con Hispania de Antonino. En efecto, el respeto y afecto del emperador hacia su suegro M. Annius Verus (P.I.R. 2, I, 118,.$^{\circ}$ 694) ha sido exaltado por Carcopino y J. Beajeu (CARCOPINO, 1949, 315; BEAUJEU, 1955, 280 ss; S.H.A., Pius, IV, 1-2), oponiéndose a la teoría de Lacourt-Gayet (LACOURT-GAYET, 1888, 30). J. Carcopino defiende la realidad histórica en el sentido que las ligaduras familiares debieron existir entre Adriano y M. Annius Verus, el cual fue siempre muy estimado por Adriano, y su origen estaba muy lejos al punto de nacimiento del propio emperador, pues era natural de Ucubi (la actual Espejo, en la provincia de Córdoba) (S.H.A., Marcus, I, 4; ETTIENE, 1958, 463-464).

El concepto de Pax Romana debe entenderse, en esta época, en el sentido de paz civil interior. Este reinado no careció de agitaciones y guerras, aunque, éstas son de tamaño menor en comparación a las que tuvieron sus predecesores, en especial Trajano. Se levantaron las tribus de Mauretania, pero se las pudo rechazar hacia la cordillera del Atlas. En el año 139 se registra en Britannia, una sublevación de los pueblos Brigantes (pueblo celta, establecido en la zona del actual condado de York, en Britannia que ya tuvieron que ser sometidos por Cerialis entre los años 71 al 74; estaban emparentados con otros pueblos del mismo nombre situados en el Sureste de Irlanda y Noroeste de la Península Ibérica). La sublevación fue vencida por las legiones establecidas en Britannia: la II Augusta, VI Victrix y la XX Valeria Victrix, teniendo como mando de todas ellas al legatus Q. Lollio Urbico. Este movimiento junto con las periódicas incursiones de los pictos (pueblos de Caledonia, la actual Escocia), decidió al emperador a construir en el año 142 una nueva muralla en Britannia, el Vallum Antonini, más al norte que la de su antecesor (el Vallum Hadriani); esta muralla, situada en la parte más estrecha de Escocia (entre el Firt of Forth hasta Clyde), se entendía que sería sólo una primera línea defensiva, por lo que carecía de la solidez de la de Adriano, en su mayor parte era de tierra, sobre basamento de piedra y fue construida con mucha premura). El Vallum Hadriani estaba situado unas setenta millas romanas más al sur, y sería el verdadero parapeto (ASKEW, 1951; AUSTEN-BREZE, 1979, 115-126; BIRLEY, 1973; BREEZE-DOBSON, 1972, 182-208; BRUCE, 1933; BRUN, 1952; CASEY, 1984; COLLINGWOOD, 1925-1926, 193-202; 
COLLINGWOOD-MYRES, 1937; DRUMMOD, 1981; DYSON, 1985; FORDE-JOHNSTON, 1978; GOODCHILD, 1941, 1-8; HARRIS-HARRIS, 1965; HEITLAND, 1921; HIND, 1977, 229-234; HOLDER, 1982; HOME, 1948; JONES, 1976; LUTTWAK, 1975; MOTHERSOLE, 1922; MOWAT, 1904, $138 \mathrm{ss;}$ RICHMOND, 1947; RICHMOND, 1950, 43-57; ROSSI, 1966, 240 ss; SALWAY, 1967; SHOTTER, 1980, 1-15; SIMPSON-RICHMOND, 1935, 1-18; STEVENS, 1955, 384-403; STEVENSON, 1949; TODD, 1981; TOYNBEE, 1924, 142-143; TOYNBEE, 1964; WILSON, 1979, 1 ss), no obstante, la muralla de Antonino estaba mejor dispuesta estratégicamente, y en algunos sentidos era mejor que la de su antecesor (KEPPIE, 1975-1976, 61-68; ROBERTSON, 1949, 99-111; ROBERTSON, 1948, 99 ss; ROBERTSON, 1960; STERR, 1965, 35-41; VON HAGEN, 1973). El emperador quiso dejar mención de este hecho para la posteridad, al conmemorarlo en sestertius, acuñados entre los años 140 al 144, donde se muestra a la imagen simbólica de Britannia, sentada sobre una roca, portando lanza y estandarte y reposando su brazo izquierdo sobre un escudo (MATTYNGLY-SYDENHAM, 1930, n. ${ }^{\circ} 742$ ).

Esta misma política es aplicada en el limes del Rhin-Danubio. En el año 160 en Germania Superior, el emperador ordena el desplazamiento del limes hacia el Este, estableciendo en el enclave de Lorch, un enlace con el limes de Raetia, construido por Domiciano en el año 84. Este muro, al revés que el de Inglaterra, se hizo de piedra, al ordenar el emperador la retirada de las empalizadas de madera mucho menos seguras y susceptibles de ser incendiadas. Se amplió la defensa con la construcción de torres y castillos de guarnición igualmente de piedra. La razón de ello estribaba en que el limes germano entrañaba mucho más peligro, al haber mayor cantidad de pueblos acumulados tras ellos, esperando una oportunidad para pasar a territorio romano, aunque la razón principal era que esta muralla era la única, no existiendo ni en ese momento, ni posteriormente, una segunda línea defensiva en toda la Europa Continental, a diferencia de Britannia, donde, como hemos visto sí exitía (ALTHEIM, 1952, $56 \mathrm{ss}$ ). Esta política de construcciones sólidas, demostró su eficacia, cuando hacia los años 154-155, se produjo una ofensiva limitada hacia Escocia.

En una ocasión, una sublevación campesina en Egipto estuvo a punto de costarle el trono e incluso la vida a Antonino. El peligro para Roma estribaba en que Egipto, junto con el Norte de Africa, y Sicilia, y en menor medida, Hispania, suministraban la totalidad del trigo a Roma. La plebe romana se acostumbró con el paso de los años a vivir gratuitamente de la annona, esto es, del reparto de víveres, fundamentalmente trigo y aceite a todos los empadronados en Roma, entre los que se encontraba la guardia pretoriana, a lo que había que añadir generosas entregas de dinero en efectivo por parte de los emperadores en fechas señaladas; su falta daba lugar a fuertes tumultos que convertían al emperador de facto en el rehén de sus propias tropas y conciudadanos. Esto es lo que le sucedió a Antonino, se produjeron movimientos en la capital, durante los cuales la multitud casi lapida al propio emperador. La Historia Augusta dice que se vio forzado a organizar distribuciones de pan, vino y aceite costeándolas él mismo y repartiéndolas gratuitamente en la Urbe (S.H.A., Pius, VIII, 11; VAN BERCHEM, 1939).

Hubo sublevaciones entre el 145 al 152 en Mauritania Tingitana (una zona a la que Antonino Pio prestó particular atención, como hemos visto más arriba), lo que provocó importantes movimientos de tropas como relata la Historia Augusta (S.H.A., Pius, V, 4); se produjeron disturbios entre los años 157 al 158, en una Dacia aún mal pacificada, como relata la misma fuente (S.H.A., Pius, IV, 4; C.I.L., III, 1416; DAICOVICIU, 1965; FORNI, 1960, 225-232). Lo que dio lugar a la división tripartita de la Dacia el año 159 en Dacia Porolisense, Apuliense y Maluense. Por otra parte, Antonino tuvo la suerte de que la debilidad interna del reino de los partos no les permitiese hacer ninguna guerra de conquista, pese a que estos habían sufrido importantes humillaciones desde la época de Trajano.

Todos estos hechos que, por separado, parecían tener poca importancia, eran los primeros síntomas del colapso que se avecinaba con el gobierno de Marco Aurelio. Si Trajano había sido un emperador eminentemente ofensivo (Conquista de la Dacia, ampliación de las fronteras hasta el río Tigris... etc). Adriano paró las conquistas y se puso a la defensiva (construcción del Vallum Hadriani, retracción de la frontera del Tigris al Eufrates... etc.). Este proceso es aún más marcado con Antonino Pio que quiso cerrar sus fronteras ante la gran ola bárbara que se avecinaba, para ello, se ampliaron los fuertes y empalizadas en todas partes, y por primera vez hubo mayor cantidad de tropas auxiliares autóctonas, se deportaron los rebeldes a otros lugares, como es el caso de numerosos grupos de britanos, al igual que una importante 
cantidad de numeri fueron destinados a la defensa de las fronteras. Con Marco Aurelio, ya no cabrían los movimientos disuasorios; el emperador-filósofo, por excelencia, tuvo que dedicar la mayor parte del tiempo de su gobierno a combatir y defender los límites del Imperio, casi al mismo tiempo y en todas partes. Y como indica Ernest Hohl (HOHL, 1975; SIRAGO, 1974; MONTENEGRO, 1978) para referirse a la época en que trascurrió el gobierno de Antonino Pio: «El imperio llega bajo su mando a la cumbre de la civilización pacífica. Bajo el régimen pacífico del emperador el conjunto de la cultura helenístico-romana, dilatada sobre el mar Mediterráneo, aparecía al orador griego contemporáneo, Elio Arístides, como una única ciudad, como un único Estado humano, regido en sabia unidad. $\mathrm{Y}$, sin embargo, el brillo exterior no debe engañarnos y ocultarnos el vacío espiritual de la época, que era ya incapaz de recogerse para obra alguna creadora. El sentimiento de que el Imperio había llegado a su edad senil estaba ampliamente difundido; pero sintiéndose el mundo cansado y viejo hubo de entregarse y a la quietud sucedió pronto el retroceso. El gobierno de Antonino Pio representa la calma antes de la tempestad, que ya se desencadena con los emperadores siguientes. Italia, la cuna del imperio, hallábase innegablemente en decadencia económica. La industria y el comercio hubieron de retroceder en la misma medida en que las provincias iban haciéndose económicamente independientes. La gran propiedad, los proverbiales latifundios, que se encontraban en manos de los senadores imperiales y otras personas ricas, aumentaban sin cesar y se tragaban a las fincas pequeñas. Los libres labradores de antaño se convirtieron en arrendatarios. Síntoma grave de la decadencia popular en Italia fue el descenso de la población, que Nerva y sus sucesores intentaron contener mediante disposiciones político-sociales, estableciendo en las llamadas alimentaciones fundaciones en favor de familias de muchos hijos».

A diferencia de su antecesor Adriano el más ilustre e infatigable viajero que tuvo el mundo romano, Antonino Pio se desplazó poco o nada, apenas si están constatados unas visitas a sus fincas agrícolas en la región italiana de la Campania, y sin embargo, ningún otro emperador antes que él tuvo más renombre e importancia en todo el mundo conocido y especialmente en Oriente, los hechos así lo demuestran sabemos, por ejemplo, que el emperador gozaba de gran autoridad. Esto ha quedado demostrado por las embajadas que llegaron hasta él desde la India, Hircania o Bactriana, y por su intervención en la política interna del Bósforo, de Iberia de Cólquida y de Armenia. La Historia Augusta lo relata detalladamente: «El rey Farasmenes vino a Roma a visitar a Antonino y tuvo más deferencias con él que con Adriano. Nombró a Pacoro rey de los Lazos. Una carta suya fue suficiente para hacer desistir al rey de los partos (Volageses III) de sus ataques a los armenios y bastó también su autoridad para hacer venir de Oriente al rey Abgaro. Puso término a los litigios de los reyes. Rechazó por completo las pretensiones del rey de los partos que volvía a pedir la silla real que Trajano le había arrebatado. Volvió a enviar a Rhoemetalce al reino del Bósforo, después de haberse enterado del pleito que mediaba entre él y Eupator. Paró en el Este las correrías de los Alanos. Envió tropas al Ponto para auxiliar a los habitantes de Olbiópolis contra los tauroescitas y venció a estos imponiéndoles la obligación de entregar rehenes a los olbiopolitas. Nadie tuvo, ciertamente tanta autoridad sobre las naciones extranjeras» (S.H.A., Pius IX, 610; WILLIANS, 1967, $470 \mathrm{ss}$ ).

Es evidente, que el fortalecimiento del poder imperial se tradujo en una ampliación y expansión del comercio romano, que hasta el siglo II sólo se circunscribió al ámbito del Mare Nostrum. Una vez que Antonino era conocido y respetado, tanto política como comercialmente, en la India y Bactriana, nada le impedía intensificar sus relaciones comerciales con el Extremo Oriente. Una serie de acontecimientos favorables tuvieron lugar en el año 165, muy poco después de la muerte de Antonino, Armenia acababa de ser reconquistada, Mesopotamia, tras la derrota de los partos, se convirtió en un territorio romano más. En ese mismo año partió una embajada hacia China. En el año 166, un año después, apareció en la corte del emperador chino Huan-Ti, una serie de mercaderes griegos o sirios que se decían embajadores del emperador An-Tun Marco Aurelio Antonino) y realizaron conversaciones para establecer un comercio directo entre los países del Imperio Romano y la China; se sabe que el emperador Huan celebró en el Palacio Imperial ceremonias taoistas y budistas por la salud del emperador Marco Aurelio y por las buenas relaciones de los dos alejados imperios (MAZZARINO, 1980, 335); igualmente hay que mencionar que en recientes excavaciones en el Delta del río Mekong, en 
la localidad de Oc-Eo, en Vietnam, han aparecido aurei de Antonino Pio (ALTHEIM, 1964, 109). Este comercio de todas formas, se realizaba desde siglos antes a través de las rutas caravaneras que atravesaban, al norte y al sur, las amplias mesetas, llanuras y desiertos del Asia Central, hasta llegar a la región de Palmira y los puertos y costas de Asia Menor, Palestina y Siria, trayendo, además de las especies, el producto oriental más querido en Occidente: la seda. A través de estos productos, se establecieron unas relaciones hasta entonces nunca vistas entre Roma (posteriormente, Bizancio) y la India, Ceilán, el Sudeste Asiático y las regiones occidentales y del sur de China. El comercio marítimo entre Occidente y la India, que tradicionalmente se realizaba por vía marítima, en navegación de cabotaje, a través de las costas de la India, Persia, Mesopotamia, Arabia y el Mar Rojo, para, al final, desembarcar a través del mar Rojo, en los actuales puertos de Eliat (Israel), Aqaba (Jordania) o Suez (Egipto). Esta ruta marítima «de las especies», resultaba, en ocasiones, demasiado larga y expuesta a las tormentas o ataques de los piratas del Mar Rojo o del Océano Indico; por lo que, a partir de la llegada a China de los embajadores romanos, una empresa mercantil privada romana, la de los Maes Titianos, envió exploradores para establecer un comercio regular entre Roma y la India por tierra, basándose en las antiguas rutas caravaneras (ALTHEIM, 1964, 109, nota 6). La India mantenía en estos años una actividad comercial no conocida hasta entonces: en la década de los años 40 del siglo II diversos reinos del subcontinente indio enviaron embajadas a China por vía terrestre y, especialmente, marítima; gracias a su especial relación tanto con Roma como con China los hindúes resultaron particularmente beneficiados en su condición de intermediarios. Roma se vio en la obligación de instalar en Asia empresas textiles, principalmente en Egipto y Asia, para elaborar y trasformar en productos confeccionados la seda que le llegaba de China a través de la India. Desgraciadamente, la peste declarada en Seleúcida, la invasión de los marcomanos en el invierno de los años 166 al 167, mandados por el rey Balomario, obligó a Marco Aurelio a desplazar importantes contingentes de tropas hacia el Danubio Medio para proteger el siempre peligroso limes de Raetia y Panonnia (BARADEZ, 1965, 7582; DRINKWATER, 1984; GEROV, 1961, 107 ss; HATT, 1959; JULLIAN, 1913-1926; MIHAILOV, 1961, 42 ss; MOMMSEN, 1968 (reimp.); MOSCY,
1959, 282 ss; MOSCY, 1962, 516-517; MOSCY, 1974; MOSCY, 1976, 286-288; POLASCHEK, 1937, 971-1048; STEVENSON, 1939; SYME, 1965, 342 ss; THOMAS, 1964 WAGNER, 1951-1952, 26 ss; WIESNER, 1963); en la misma medida, Roma tuvo que abandonar posiciones avanzadas en el Eufrates Inferior y el Golfo Pérsico, por lo que la navegación costera con la India se vio abocada a serios peligros, y con el tiempo disminuyó hasta hacerse inexistente; lo mismo le sucedió al comercio con China que, forzosamente, tenía que pasar por el de la India (MAZZARINO, 1980, 335).

El Africa negra y desconocida se convirtió en otro objeto primordial en la política de Antonino Pio; la reconstrucción de ciudades como Cartago, o la construcción de calzadas a través de las regiones casi inexploradas de la cordillera del Atlas por la Legio III Augusta en el año 145, como así lo demuestran los miliarios, (VON HAGEN, 1973, 51) atestiguan esta afirmación. Los motivos no eran solamente de exploración sino también eminentemente comerciales: del interior del Continente se exportaban animales para los circos de todo el Imperio y especialmente de Roma, piedras preciosas, oro, marfil, esclavos... etc.

Incluso el Norte de Europa recibió la visita de las legiones y de los exploradores romanos, la construcción del Vallum Antonini en las proximidades de Escocia y las incursiones de conocimiento en la misteriosa Hibernia (Irlanda) así lo demuestran.

¿Todos estos avances en el conocimiento de pueblos y lugares se debió sólo a la prosperidad y el prestigio de los emperadores romanos del siglo II? Evidentemente, no. Los conocimientos técnicos y geográficos fueron a la par que las exploraciones. El mismo año de la muerte de Antonino Pio, el 160, fallece en Canope, el astrónomo, matemático y geógrafo griego Claudio Ptolomeo, que habría nacido unos setenta años antes. Ptolomeo escribió una Geografía, que describe en ocho libros más de ocho mil poblaciones del mundo conocido en Europa, Africa y Asia, además de la longitud y latitud de su emplazamiento; estas coordenadas fueron hechas de forma muy precisa gracias a los conocimientos matemáticos de Ptolomeo, conocimientos que también utilizó como base de su gran tratado de astronomía conocido como Almagesto; en él se sitúa con precisión, como indica Santos Mazzarino, una «Isla de la Plata» que parece corresponder, nada menos, que a Sumatra (MAZZARINO, 1980, 335). 
Pero no solamente Claudio Ptolomeo es el fruto de esta época. Antonino buscó el apoyo de las clases cultas de todas las provincias desarrollando para ello en los grandes núcleos urbanos de todo el Imperio una enseñanza superior subvencionada por el Estado para aumentar la cultura de las clases adineradas provinciales, a quienes otorgó la ciudadanía romana sin mayores problemas. Así, el emperador mandó un edicto a la Asamblea de la provincia de Asia prometiendo inmunidad de ahora en adelante, a los oradores y otros maestros públicos. Nerva puso en marcha y Trajano desarrolló un plan para educar a los huérfanos italianos por medio de fondos procedentes de las hipotecas agrarias, para las que el Estado anticipaba los capitales a bajo interés, ayudando al mismo tiempo a los agricultores y a los huérfanos; difícilmente se podría encontrar un mejor ejempio del Estado social desarrollado por los emperadores de la dinastía de los Antoninos. Posteriormente, y tras la muerte de la esposa de Antonino, Faustina, este plan se hizo extensivo a las niñas, (Puellae Faustiniae) dedicado al recuerdo de la emperatriz. (S.H.A., Pius, VI, 7; VIII, 1).

Quizás agradeciendo la inmunidad prometida, Elio Aristides, filósofo de Hadriani, ciudad situada al noroeste de Asia Menor, escribe su Alabanza a Roma bajo el gobierno de Antonino Pio en el año 143 d. de J.C. Arístides es un apologista de la dinastía de los Antoninos en general y de Antonino Pio en particular: su Elogio de Roma es una de las mejores fuentes de conocimientos del siglo II (BALSDON, 1979, 179). Elio Arístides suponía, en frase de J.V.P.D. Balsdon: «La mayor expresión literaria de lo que la 'Edad Oro' podía significar para el mundo de Adriano y de los Antoninos» (BALSDON, 1979, 179; BLEICKEN, 1966-1967, 225 ss; BOULANGER, 1922, 26 ss; BOULANGER, 1923; MESK, 1909, 5 ss; OLIVER, 1953; PAVAN, 1962, 81 ss).

«Ahora todas las ciudades griegas prosperan bajo vuestra hegemonía y los monumentos que se dedican en ellas y todos sus ornatos y comodidades son bellos suburbios en vuestro honor. La costa y el interior se han llenado de ciudades algunas de nueva fundación, otras engrandecidas por vosotros... Preocupándonos grandemente de los griegos, como si fueran vuestros padres adoptivos, constantemente les tendéis la mano, y cuando están postrados los levantáis. Dejáis en libertad y autonomía a quienes de ellos fueron antaño los más nobles y poderosos, y guiáis al resto moderadamente con mucha consideración y pre- visión. Como en fiesta, el mundo civilizado depone las armas que fueron su antigua carga y se entrega a las galas y a toda clase de alegres pensamientos, con posibilidad de realizarlos. Las demás rivalidades han desaparecido de las ciudades y únicamente les queda esta pugna ¿cómo podría mostrarse cada una más bella y atractiva?... Jamás dejan de afluir de parte vuestra beneficios para las ciudades y es imposible determinar cuáles han sido las más favorecidas, porque vuestra benevolencia con todas es la misma. Relumbran de esplendor y encanto las ciudades, y la tierra entera ha quedado embellecida como un jardín... Por ello, es justo compadecerse únicamente de aquellos que están fuera de vuestra hegemonía, si es que en realidad alguno hay, porque se pierden tales bendiciones. Asimismo sois vosotros quienes mejor habéis demostrado el general aserto de que la Tierra es la madre de todos y la patria común. Ahora, ciertamente, le es posible a griegos y no griegos el viajar donde les plazca, con o sin sus bienes, fácilmente, como si de patria a patria se pasara. Ni las puertas de Cilicia ni el paso a Egipto entre arenas a través del país de los árabes, ni las tribus inhospitalarias de los bárbaros causan temor, pues para estar seguro basta ser ciudadano romano, o mejor dicho ser uno de los que están unidos a vuestra hegemonía. Homero dijo: "La Tierra es común a todos», y habéis hecho que resultara cierto su acierto. Habéis medido y registrado el campo en todo el mundo civilizado; habéis tendido sobre los ríos puentes de todas clases, trazado calzadas a través de las montañas, y colmado los lugares yermos de lugares donde repostar; habéis acostumbrado a todas la regiones a llevar una vida organizada y ordenada» (ARISTIDES, 94-96).

Para Elio Arístides, el Imperio estaba protegido por el «anillo de acero», las legiones, que se extendían por todos los limites, europeos, asiáticos y africanos, los soldados eran reclutados en las ciudades del Imperio, dando lugar a ejércitos autónomos de los propios países, por lo que tenían una mayor motivación a la hora de la defensa, el mundo romano vivía en paz, sus ciudades se desarrollaban por la magnanimidad de Antonino y sus predecesores, las comunicaciones se desarrollaron hasta un punto nunca alcanzado antes, la red de calzadas atravesaba en todas direcciones el Imperio, y gracias a ello, el comercio florecía. El emperador asumía y juzgaba todos los problemas del Imperio en persona. Quizás, lo más importante que sucedió en todo su 
gobierno era que la ciudadanía romana se dio con una abundancia no conocida hasta entonces, no sólo las clases pudientes y cultas la recibieron, sino también comerciantes y burgueses en general de todos los rincones del Imperio, creando un importantísimo núcleo de «ciudadanos» que acababan identificándose con la ideología y la política imperial. Tal era lo que pretendía Arístides, que así hablaba de Roma:

«De todos los rincones de la Tierra y de los mares afluyen a vosotros los productos de todas las estaciones y de todos los países, los de los ríos y de los lagos, y todo cuanto pueda crear la industria de los griegos y de los bárbaros. ¿Se desea contemplar todos estos productos? Es menester recorrer la tierra entera o habitar en Roma. Aquí se halla siempre en abundancia todo cuanto la naturaleza y la industria producen en todos los pueblos. A cada estación del año, sobre todo en otoño, tantos navíos de transporte vienen a atracar a los muelles del Tiber, que Roma es, en cierta manera, el mercado universal del mundo. Los frutos de la India y de la Arabia Feliz son tan numerosos entre vosotros, que se puede pensar que todos los árboles de aquellos países se han quedado sin frutos. Si los hindúes o los árabes necesitan productos de su suelo, a Roma tendrán que venir a buscarlos. Los tejidos de Babilonia, las joyas de la barbarie más lejana, llegan a Roma en mayor cantidad y con mayor facilidad que si se tratara de transportar a Atenas un producto de Naxos o de Citnos. Vuestro dominio agrícola comprende Sicilia, Egipto y todas las tierras cultivadas de Africa. Es un continuo ir y venir de navíos a vuestros muelles. Aquí en el punto de reunión de todo cuanto el comercio, la navegación, la agricultura, las minas, la industria de todos los tiempos y de todos los pueblos pueden producir; de todo cuanto la naturaleza, en fin, puede criar. Lo que no se encuentra en vuestro país, no existe, no puede existir, en ninguna parte» (ARISTIDES, 94-95).

«Era evidente que el régimen pacífico del emperador, el conjunto de la Cultura HelenísticoRomana, extendida por todo el mar Mediterráneo, aparecía a Elio Arístides como una única ciudad, como un único Estado humano, regido en sabia unidad. La época de Antonino, es un período en el que todo tuvo cabida, desde el fervor religioso, pasando por la superstición que aparece en las páginas de Apuleyo, hasta la devoción de Arístides y, sobre todo, el crecimiento de la Iglesia Cristiana y su lucha contra las sectas gnósticas, las cuales crecían con gran impulso. En cuanto al Cristianismo, Antonino Pio estuvo inclinado a la bondad de temperamento y a mostrar indulgencia; pero tal indulgencia estaría limitada por el principio: dum ne quid contra disciplina» (MATTINGLY, 1940, CI). Antonino, en contra de lo que realizó Adriano, prefirió proteger a los dioses romanos frente a un helenismo idealizado $y$ trasnochado, igualmente hizo frente a la marea de divinidades orientales que extendían su culto por Italia y todo el Imperio rechazando la influencia de las religiones orientales y que tanta importancia adquirirían desde finales del siglo II.

En otro orden de cosas, «los elementos ideológicos del Principado, una de las bases del poder imperial, iban unidas a unas directrices políticas concretas; línea de 'movimiento' con Trajano, 'estabilización' con Adriano e 'inmovilismo' con Antonino Pio» (PFLAUM, 1966, 143 ss). Este «inmovilismo», es con mucho, una de sus características más destacadas, Antonino rehusó de forma continuada a las presiones de sus generales a toda conquista que ampliase aún más el Imperio, prefirió fortificarse en el interior del Imperio y esperar desde allí los avatares del destino. Su máxima era la de Escipión el Africano «que prefería conservar un ciudadano que matar mil enemigos» (DIO CASSIO, LXX).

La propia Historia Augusta hace referencia a la política sumamente conservadora del gobierno de Antonino Pio: «no destituyó a ninguno de los que Adriano había puesto en cargos públicos y fue tal su constancia que mantuvo a los buenos gobernadores en sus provincias siete y hasta nueve años. Tampoco destituyó a ningun magistrado que no hubiese dado lugar a ello. Aunque el prefecto Gavio Máximo, después de llevar veinte años al mando de los pretorianos tuvo que ser destituido por un escándalo surgido al difundirse el rumor de que había conseguido el puesto gracias a una concubina del emperador» (S.H.A., Pius, V, 3; VIII, 7-9). Potenció la institución del Consilium Principis creada por su antecesor, institución a la que él mismo pertenecía junto con los juriconsultos Vindio Vero, Salvio Valente, Volusio Meciano, Ulpio Marcelo y Iavoleno (S.H.A., Pius, XII, 1). La misma fuente, antes indicada, nos dice que «las provincias prosperaron bajo su gobierno» (S.H.A., Pius, VII, 1), cosa que hemos de creer si tenemos en cuenta el gran número de obras públicas que se realizaron y que 
hemos relatado más arriba; no obstante, carecieron de las visitas e inspecciones que realizó su vitalista antecesor. La misma Historia Augusta informa que evitó los viajes, pues decía, con razón, que los viajes del emperador acompañado de su séquito e impedimenta resultaban muy gravosos para los magistrados y ciudadanos de las provincias, quedando muchos de ellos virtualmente arruinados después de una visita imperial (MATTINGLY -SUTHERLAND, 1926, 590592). Ello no le impedía estar siempre al corriente de las rentas públicas y de la contabilidad de las diversas regiones del Imperio (S.H.A. Pius, VII, 8). Estas actuaciones dejan claro que las diversas regiones del Imperio mantenían una profunda crisis financiera que se remonta al esfuerzo que tuvieron que hacer para sufragar las costosas campañas de Trajano, los viajes de Adriano, y la continua annona a la ciudad de Roma. Antonino, en la medida de lo que pudo, suavizó este estado de cosas: «devolvió el Aurum Coronarium entregado por Italia, y la mitad de lo que habían aportado las provincias» (S.H.A., Pius, IV, 10). «En todo el Imperio rebajó los tributos, y hacía rendir cuentas de ellos a los procuradores» (S.H.A., Pius, VI, 1-2). «Llegó a hacer préstamos de su fortuna personal al interés más bajo de la época, el cuatro por ciento (S.H.A., Pius, II, 8). Ya Adriano había proclamado a través de la propaganda imperial numismática la abolición de los impuestos atrasados que no se habían podido recoger (cosa que Adriano había conmemorado en sestertii con la inscripción: Reliqva Vetera $H S$. Novies Mill. Abolita S.C. En dicha moneda se muestra al lictor prendiendo fuego a un montón de papiros de deudas, ante él varios ciudadanos dan vítores y aclaman a Adriano (GAGE,1933 165). Además el sistema de los congiaria o liberalitates estaba plenamente establecido en el siglo II, por lo cual no pudo dejar los repartos de bienes y dinero en ocasiones especiales. «Distribuyó un congiarium al pueblo y añadió un segundo donativo a los soldados». «Hizo famosísimas las nupcias de su hija Faustina al desposarse con Marco Antonio hasta el punto de contribuir con un donativo a los soldados» (S.H.A., Pius, VII, 11). Todo ello no fue óbice para que a su muerte se hubiera acumulado en las cajas del Estado la enorme cifra de seiscientos setenta y cinco millones de denarii, la misma cifra que había dejado Tiberio.

Por otra parte, las viejas familias del período republicano estaban en completo declive, cuando no habían desaparecido completamente, desde que Adriano había puesto la administración en manos de los miembros del orden ecuestre; eran ellos los representantes del Estado tanto en Italia como en las provincias, también acaparaban buena parte de los puestos del Senado. Antonino Pio representaba, por el contrario, al tipo del aristócrata rural con sus fincas en Campania; a este orden social pertenecían, todavía, una buena cantidad de individuos que habían adquirido sus fincas en los dos últimos siglos, y que habían ido ampliando gracias a compras, préstamos, donativa, hipotecas, o simplemente, por despoblamiento del campo que ya empezaba a notarse de forma alarmante en la segunda mitad del siglo II, hasta el punto que, durante el gobierno de Marco Aurelio, llegase a hablarse de los Agri Deserti. Un buen ejemplo del aristócrata enriquecido era el cortesano Herodes Atico que obtuvo en parecidas fuentes sus fabulosas fortuna. P. Grainder, lo ha descrito como «un millonario del mundo antiguo» (MAZZARINO, 1980, 135; S.H.A., Pius, IV, 9).

Otro problema de gran importancia durante el gobierno de Antonino fue el de la sucesión al trono. Santos Mazzarino, lo plantea de la siguiente manera: «Adriano adoptó primero a Elio Vero, y tras la muerte por tuberculosis de este último, a Antonino que tenía el nombre de Pio por su pietas hacia Adriano y por la presión que ejerció sobre el Senado para conseguir la apoteosis de Adriano. Antonino tenía de su matrimonio con Faustina la Mayor dos hijos varones y dos hijas, pero los dos hijos varones, y la mayor de las hijas murieron; por lo cual él mismo también quedó obligado a adoptar a su sucesor, y lo hizo en las personas de Marco Aurelio Antonino, esposo de la única hija que le quedaba a Antonino, Faustina la Menor y Lucio Vero (hijo de aquel Elio Vero que Adriano habia adoptado antes de hacer lo mismo con Antonino tras la muerte de aquel). En este sentido, se desarrolla el problema de tipo ideológico de si la adopción constituye el mejor medio para configurar en sentido tradicional el ideal monárquico del Estado Romano; no sólo la sucesión de Antonino Pio era concebida en el plano de la adoptio del optimus, sino que la adopción de dos optimi, se configuraba de manera diárquica con una mayor garantía de constitucionalidad en relación al ideal típico del Senado Romano» (MAZZARINO, 1980, 327-328).

El mismo autor señala que esta monarquía dual, era mucho más apta para gobernar un imperio de tanta extensión, y que de alguna manera recordaba al sistema de los dos cónsules de la época republicana, lo que daba mayores garantías de constitucionalidad, y por tanto, se adaptaba más al sentir del Senado romano. 
En realidad, esta diarquía, tiene dos planos distintos. Así la epigrafía y la numismática nos muestran que ambos sucesores designados reciben diferentes títulos: Marco Aurelio es mencionado como Caesar, mientras que Lucio Vero recibe el título menor de Augusti Filius, y aunque posteriormente ambos se convirtieron en Augustus, sólo Marco Aurelio recibió el título de Pontifex Maximus, el cual no fue llevado por Lucio Vero. Fue esta la experiencia de adopción más completa del siglo II y también la última. Marco Aurelio designaría como Caesar a su propio hijo Cómodo, un incapaz de soportar semejante responsabilidad, con lo cual se perdió para siempre la prudente medida seguida durante todo el siglo II de dejar el Imperio al optimus, esto es, al mejor.

Marco avanzó en las etapas sucesivas del Cursus Honorum llegando en su cargo a una cercana igualdad con Antonino Pio, mientras que Lucio Vero quedó desde el primer momento relegado a un segundo plano, actitud esta que no podemos analizar al no habernos dado las fuentes suficiente información al respecto. Pero a Marco, aún siendo aceptado, hasta que alcanzó el decimoquinto año de su tribunicia potestad no se le dio el rango de Augustus, mientras que su mujer, era ya Augusta desde el año 147 (MAZZARINO, 1980, 328-329).

M. Grant opina sobre esta época lo siguiente: «Gibbon, el primer gran analista del declive y caída del Imperio Romano, introdujo en la historiografía el término «Edad de Oro de los Antoninos», pero este término sólo se hizo plenamente verdad en el período de gobierno de Antonino. Y sin embargo, este no se distingue de otros gobiernos del siglo II en cuanto a la insistencia en los aspectos ideales de la «Edad». Antonino concentró la propaganda política monetaria de su período en los tipos de Virtus, Annona, Iustitia, Pax y Felicitas, pero también Victoria, pues el principado de Antonino fue, fundamentalmente, de paz armada. En la misma línea, se potenció el culto a los emperadores fallecidos y a los miembros de la familia imperial divinizados, de ahí las múltiples emisiones de Faustina una vez fallecida, con las leyendas Diva, Aeternitas y Consecratio. Igualmente, el Novecientos aniversario de la fundación de Roma, algo que ocurrió durante el gobierno de Antonino Pio, estuvo preludiado en numerosas referencias en monedas y medallas hacia el legendario pasado. El aniversario fue conmemorado de modo solemne. Antonino sentó un precedente al hacer representar en las monedas, con la inscripción: «la generosidad del emperador», a un elefante, de los que había procurado para que se le matara en el circo, conmemorando este nonagésimo aniversario» (GRANT, 1973, 114). El término «Edad de Oro», se refiere también a los mejores momentos del pasado imperial, desde los tiempos de Augusto, pero especialmente desde Trajano; este recuerdo del pasado glorioso fue rememorado desde el propio palacio de Antonino fomentando el estudio de la literatura, el arte y la historia griega y romana, las cuales son propuestas como el supremo ideal de la civilización. Los tiempos de Antonino fueron, al decir sus propios contemporáneos, los más estables desde el punto de vista político, cultural y religioso; nunca más volverían a repertirse. En el mismo sentido, la Historia Augusta dice: «Organizó unos juegos en los que exhibió elefantes, hienas, tigres y rinocerontes, cocodrilos e hipopótamos y toda clase de fieras de todas partes del mundo. Hizo correr también a cien leones acompañados de tigres en una sola carrera» (S.H.A. Pius, VIII ,1; X, 2; POESCHL, 1941, 423 ss).

Antonino dedicó una buena parte de la obra de su gobierno a humanizar la legislación, a través de sus jurisconsultos; estas leyes iban dirigidas, fundamentalmente, a resolver la situación de los más pobres o necesitados. En general, el Derecho Penal Romano tuvo una importante relajación, el propio emperador ordenó que, en lo sucesivo, las leyes fuesen aplicadas favoreciendo la presunción de inocencia. Asimismo las fuentes nos han dejado una amplia relación de sus medidas. Entre otras cosas, se permitió formar parte de los distintos gremios profesionales tanto a hombres libres como a esclavos, los cuales, de esta manera, tenían la posibilidad de enriquecerse e, incluso, comprar su libertad con su trabajo; se dio libertad inclusive para afiliarse a dos o más gremios (S.H.A., Pius, X, 8). Se prohibió a los propietarios de esclavos darles muerte; sin embargo, y a pesar de lo expuesto, la situación real de esclavos y libertos no mejoró de forma sustancial: los propietarios de esclavos seguían teniendo muy amplios derechos sobre los mismos, de ello da fe el rescripto de Antonino Pio dirigido al procónsul de la Bética, Aelio Marciano, con motivo de la sublevación de los esclavos de un propietario llamado Julio Sabino: el hecho debió de tener alguna trascendencia ya que el emperador ordena la investigación de los hechos y permite la intervención del gobernador, siempre y cuando no se conculquen los derechos del señor sobre sus esclavos (C.I.L., VI, 29722); se pre- 
tendía con ello la humanización del trato pero de ningún modo se cuestionaba la esclavitud en sí. No obstante, si se constataba que la crueldad de los amos llegaba a límites vergonzosos, estos quedaban obligados forzosamente a vender a sus esclavos, previendo que: «era en el interés de los amos, en contra de la crueldad, el hambre o las injurias intolerables a aquellos que la soliciten con justicia» (GRANT, 1973, 147-148). Sabemos por las fuentes, que durante el gobierno de Antonino Pio, a medida que descendía el número de esclavos, gracias a la falta de guerras y a las manumisiones, descendía también la producción, lo que implicaba una mayor explotación de los esclavos restantes. Se daba el caso, incluso, que muchos señores liberaban a sus siervos para que una vez convertidos en libertos siguiesen siendo clientes de su antiguo amo el cual les exigía parte de sus honorarios en virtud de su calidad de cliente (DIGESTO, 1870, I.6.2). El patrono, a su vez, también tenía que cumplir las pesadas cargas económicas que le imponía su municipium.

Antonino falleció el 7 de marzo del año 161 en la ciudad de Lorio. Viendo llegar su último momento la Historia Augusta dice que encomendó la Nación y su hija a Marco Aurelio, en presencia de los prefectos. Antes de morir dio la última consigna al prefecto de la guardia: Aequanimitas, (S.H.A., Pius, XII, 4-7). Esa «ecuanimidad» para resumir como lema final, la ideología de todo un gobierno así como la ambición de este emperador pacífico que a diferencia de su antecesor y de su sucesor en el trono no era ni un intelectual ni un filósofo. Previamente, la estatua de oro de la diosa Fortuna, por la que los emperadores sentían especial veneración, y en especial Antonino que en sus monedas califica a esta diosa de Obsequens, es decir, favorable a sus deseos, ordenó fuese llevada al dormitorio de Faustina (S.H.A., Pius, XII, 5; GRANT, 1973, 163), indicando con ello que le trasfería el trono a ella y a su esposo Marco Aurelio Antonino.

Fue enterrado en el Mausoleo de Adriano. El Senado, que lamentó muchísimo su pérdida, le colocó espontáneamente entre los soberanos divinizados por unanimidad de todos sus miembros. Se fundó un nuevo colegio sacerdotal, el de los Sodales Antoniniani, consagrado a su culto, y se le erigió en su honor una columna en el Campo de Marte, así como se le dedicó un templo y juegos circenses en su honor. Antonino pasó a formar parte de los dioses del hogar familiar y patrio de los Genii tutelares del Mundo Romano (S.H.A. Pius, XIII, 4).

\section{BIBLIOGRAFÍA}

\section{Obras Clásicas.}

AURELIUS, M., 1977: Ei (Meditaciones), Gredos, Madrid.

CASSIUS, DIO, 1969: Historiae. Loeb Classical Library. LondonCambridge-Massachusset.

C.I.L., (Corpus Inscriptionum Latinarum), VI, Berlín, 1893-1955.

DIGESTA IUSTINIANI AUGUSTI, 1870: ed. TH. Mommsen, Berlín.

PROSOPOGRAPHIA IMPERII ROMANI (P.I.R) 2, 1897-1898: I, 118, n. ${ }^{\circ}$ 694. Ed.Kebs, H. Dessau. Berlín.

SCRIPTORES HISTORIAE AUGUSTAE (S.H.A.), 1967: Antoninus. Loeb Classical Library. London-Cambridge Masschusset.

TACITUS, 1965-1968: Historiae, I, I.H. Goelzer, Les Belles Lettres, París.

\section{Obras de carácter general.}

BABELON, J., 1935: «Bronzemedaillon des Antoninus Pius, gefunden bei Querfunt», Münzensammler, VlIl, 87 ss. 1979:

BALSDON, J.V.P.D., 1979: Los romanos, Madrid.

BEAJEU, J., 1955: Le religion romaine a l'apogée de l'Empire, I, La politique religieuse des Antonins (96-192), París, 280 ss

BORRELLI, N., 1936: «II tipo dell'ltalio mincovnictvi Antoninú», Num. Cas. Cesk., 1 ss.

DODD, C.H., 1911: «The Cognomen of the emperor Antoninus Pius», NC, XI.

ELMER, G., 1933-1934: «Zwei neue Schaumünzen des Antoninus Pius», Numismatik, 145 ss.

ELOY, L.-THIRION, M., 1960: «Imitation d'un sesterce des Antonins provenant de la Sambre Namur», RBN, 311 ss.

GAGE, J.G., 1933: La Sociedad y la Cultura Greco-romanas 31 a J.C, 235 d.J.C. París.

GRAEFE, E., 1973-1971: «Ein zweiter Goldring mit hieroglphisch geschriebenem Namen und Titulatur des Antoninus Pius», JVEG, XXIII.

GRAINDOR, P., 1927: «Antonin le Pieux et Athenes», Rbph, VI, 753-757.

GRANT, M., 1973: El Mundo romano, Madrid.

GRENADE, P., 1950: «Le Réglament succesoral d'Hadrien», REA LII, 258-277.

GUEUNINE, L., 1924: «Aureus d'Antonin le Pieux et de MarcAuréle», RBN, 99 ss.

HAMMOND, M., 1959: «The Antonine Monarchy», Papers and Monographs of the American Academy in Rome, XIX, Roma.

HAMMOND, M., 1975: «The Antonine Monarchy: 1959-1971: $A N R W, 11,2$, Berlín-Nueva York, 1975.

HILL, P.V, 1966: «La Sequenza delle emisioni di Antonino Pio dal Iuglio al Dicembre del 138 d.C.», $B N 4$ ss.

HOHL, E., 1938: «Die angebliche Doppelbestaltung des Antoninus Pius», Klio 169 ss.

HOHL, E., 1975: «La Época Imperial Romana», en La Helade y Roma. El Origen del Cristianismo, Madrid, 474.

HOWAT, B., 1928: «Medaillon inconnu de l'imperatrice Faustine Mère, contributions aux études des médaillons patriotiques d'Antonin le Pieux de la fête Séculaire de Rome», Vjesnik Krvatskog archeoloskog drustva u Zagrebu, XV, 11 p.

HUTTL, W., 1933-1936: Antoninus Pius I,II, Praga.

JANSSEN, A.J., 1969: T. Antoninus Pius, Nimega.

KLAUSEN, R.H., 1839-1840: Aeneas und die Penaten, Hamburgo. 
LACOURT-GAYET, G., 1888: Antonin le Pieux et son temps Essai sur l'histoire de l'Empire romain au milieu du deuxieme siecle (138-161), París.

LAFFRANCHI, L., 1910: «Osservazioni numismatiche romane 1. Errata-Corrige alle date di Antonino nell'opere di Cohen», $B I N$, 37 ss.

MAGNAGUTI, A., 1950-1953: Ex Nummis Historia, IV. Monete romane da Antonino Pio alla caduta dell'Impero d'Occidente (138-476), Venezia.

MANSON, M., 1969: «Variante inédite d'un as d'Antonin le Pieux», BSFN, XXIV, 439-440.

MATTINGLY, H.-SUTHERLAND, C.H.V., 1926: Roman Imperial Coinage, II, London.

MATTINGLY H.-SYDENHAM, E.A., 1930: The Roman Imperial Coinage III Antoninus Pius to Commodus, London.

MATTINGLY, H., 1940: Catologue of the coins of the Roman Empire, in the British Museum, IV: Antoninus Pius to Commodus, Bristol-Oxford.

MAZZARINNO, S., 1980: L'Impero Romano. Bari

MILLAR, F., 1979: El Imperio Romano y sus pueblos limitrofes, Madrid.

MONTENEGRO, A., 1978: «Los preludios de una crisis: Antonino Pio», Historia de España Antigua, Madrid, 336 ss.

MOUCHMOV, N.A., 1934: Le Tresor numismatique de RékaDevnia, Sofía.

PANVINI ROSATI COTELLESA, M., 1953-1955: «Contorniato inedito del medaglione Capitolino», Cah Num LXXV, 99-107.

PHILLIPS, W.C., 1979: «Numismatic typology of Antoninus PiusVI y VII» San, X, 24-28 y 43-51.

PFLAUM, H.G., 1966: «Le valeur de la source inspiratrice de la Vita Pii à la lumière des personalités nommement citées» Historia Augusta Colloquium, Bonn, 1964-1965,143 ss.

PFLAUM, H.G., 1967: «Les pretes du culte imperial sous le règne d'Antonin le Pieux», CRAI (1967), 194 ss.

POESCHL, F., 1953: «Erlauterüngen zu einigen Stellen der Vita Antonini Pii in der Historia Augusta» WS, LXVI, 178-181.

POESCHL, F., 1941: «Die Congiaren (liberalitates) des Kaiser Antonius Pius», Hermes, 423 ss.

POESCHL, F., 1942: «Erlaüterungen zu einigen Stellen der Vita Antonini Pii in der Historia Augusta» Gymn, 147-152.

SCHELL, E., 1930: «Untersuchungen zur Geschichte des Kaiser Antoninus Pius», Hermes, LXV, 177 ss.

SCHELL, E., 1939: «Untersuchungen zur Geschichte des Kaiser Antoninus Pius», Historia 65» 177 ss.

SCHULZ, TH., 1907: Das Kaiserhaus der Antonin und der letze Historiker Roms, Leipzig.

SIRAGO, V.A., 1974: Involuzione politica e spirituale nell'Impero del II Sec, Napoli.

STEHOUWER, P.H.N.G., 1956: Etude sur Ops et Consus, Utrecht STIER, H.E., 1950: «Antoninus Pius», RAC 1477 ss.

STRACK, P.L., 1937: Untersuchungen zur römischen Reichprägung des 2 Jahrhunderts III: Die Reichprägung zur Zeit des Antoninus Pius, Stuttgart.
STROHEKER, K.P., 1966: «Die Aussenpolitik des Antoninus Pius nach der Historia Augusta», Historia Augusta Colloquium, Bonn, 1964-1965, 241 ss.

TODD, M., 1966: «Romano-British mintages of Antoninus Pius», $N C, 7$, Ser. 6, London.

TOYNBEE, J., 1925: «Some programme coin-types of Antoninus Pius», $C R, \mathrm{XXXIX}, 170 \mathrm{ss}$

TOYNBEE, J., 1959: «A bust of a Antonine boy», JRS, 39 ss.

VAN BERCHEM, D., 1939: Les distributions du blé et d'argent à la plebe romaine sous l'Empire. Génève.

V.V.A.A., 1988: Arqueología de las Ciudades Perdidas, III, Pamplona, 1988.

WALTERS, F.A., 1908: «A rare sestertius of Antoninus

Pius», NC, 194 ss.

WILLIANS, W., 1967: «Antoninus Pius and the control of provincial embassies», Historia 16, 470 ss.

ZUNTZ, G.: 1946: «Notes on Antoninus», $C Q, 47$ ss.

\section{Antinoo y su relación con Adriano:}

BABELON, E.-REINACH, T., 1925: Recueil Géneral des Monnaies Grecques d'Asie Mineure, I-IV, 1904-19I2, París

BELL, H.I. 1940: «Antinoopolis: A Hadrianic Foundation in Egypt», JRS, XXX, 37-55.

BLUM, G., 1914: «Numismatique d'Antinoos», JAN, XVI, 33-70.

DIETRICHSON, L., 1884: Antinoos, Cristiania.

HAHLAND, W., 1954: «Ebertoter Antinoos-Androkios», Wiener Jahreshefte, XLI, 54 ss.

HOLM, E., 1933: Das Bildnis des Antoninoüs, Leipzig.

KÜBLER, B., 1914: Antinoopolis, Leipzig.

KUHN, E., 1913: Antinoopolis, Ein Beitrag zur Geschichte des Hellenismus in römischen Egypteen, Göttingen, 1913.

MARCONI, P., 1923: «Antinoo. Saggio sull'Arte dell'Etá Adrianea», Monumenti Antichi. Academia dei Lincei, XXIX 161 ss.

MATTINGLY, H., 1931: «Alexandrian coins of Antinous», $N C$, 315.

REINACH, T., 1904-1912: Recueil Géneral des Monnaies Grecques de Asie Mineure, I-IV.

RIISP, J., 1945: «Two Overlooked portraits of Antinous», Acta Archeologica, XVI, $175 \mathrm{ss}$

RIZZO, G.E., 1908: «Antinoo-Silvano», Aus, III, 3 ss.

ROYSTON, L., 1983: Beloved and God, London.

SELTMAN, C., 1948: «Greek Sculpture and some Festival Coins», Hesperia, XVII.

SYMOND, J.A., 1900: Sketches in Italy and Greece, London.

SYMOND, J.A., 1883: A problem in Greek Ethics, London.

VOGT, J., 1924: Die Alexandrinischen Munzen, Berlín.

WEBER, W., 1911: Drei Untersuchungen zur Aegyptish-griechischen Religion, Heilderberg.

\section{Limes de la frontera sur del Imperio.}

BARADEZ, J., 1949: Fossatum Africae. Recherches aériennes sur l'organisation des confins Sahariens, à l'epoque romaine, París.

BARADEZ, J., 1935: «Organisation militaire-romaine de l'Algerie antique et l'evolution du concept défensif de ses frontieres», Revue Internationale d'histoire militaire, 13, 24-42.

BESNABOU, M., 1976: La resistance africaine a la romanisation, París.

BOISSIER, G., 1912: L'Afrique romaine, París. 
COMPARETE, T.L., 1976: «The Reorganisation of the Municipal administration under the Antonines», AJPH, 166183.

DI VITA, A., 1964: «El limes romano de Tripolitania», Lib Ant, 1, 65 ss.

FREZOULS, E., 1980: «Rome et la Mauretanie Tingitane. Un constant d'echec?, Ant. Afr. 16, 65-93.

GOODCHILD, R.G., 1948: «The Roman Roads and Milestrones of Tripolitania» British Military administration in Tripolitania. Department of Antiquities, $39 \mathrm{p}$.

MATTINGLY, D.J., 1940: Tripolitania: a comparative study of a Roman frontier province, Manchester 1984, A. Merighi, La Tripolitania antica, Verbania.

NICHOLS, D.A., 1978 The imperial slaves and freedmen of Africa proconsularias from Augustus to the Severi, University of Cincinnati.

PICARD, G.C., 1959: La civilisation de l'Afrique romaine, París.

REYNOLDS, J. 1978: «Hadrian, Antoninus Pius and the Cyrenaican cities», JRS, LXVIII, $111 \mathrm{ss}$.

ROMANELLI, P., 1959: Storia delle province romane dell'Africa, Roma.

SALAMA, P., 1950: Les voie romaines de l'Afrique du Nord, Argel.

SIGMAN, M.C., 1976: The role of the indigenous tribes in the roman occupation of Mauritania Tingitana, New York University.

SYME, R., 1959: «Proconsuls d'Afrique sous Antonin le Pieux», REA 61, 310 ss.

TISSOT, CH., 1884-1888: Geographie de la province romaine d'Afrique, París.

WARD PERKINS, J.B., 1952: The inscriptions of Roman Tripolitania, Roma-Londres.

\section{Faustina I}

FRAZER, A., 1960: «The Pyre of Faustina Senior», Stud. Blanckenhagen, 271-274.

GIACOSA, G., 1969: Women of the Caesars. Their Lives and Portraits on Coins, London.

HOWAT, B., 1928: «Medaillon inconnu de l'imperatrice Faustine Mere, contributions aux études des médaillons patriotiques d'Antonin le Pieux de la fête Séculaire de Rome», Vjesnik Krvatskog archeoloskog drustva « Zagrebu, XV, 11 p.

LAFFRANCHI, L., 1937-1938: «Le Auguste degli Antonini. Saggio di Cronologia numismática», Numismatica III, 110-114, IV.

MATTINGLY, H., 1943: «The Consecration of Faustina the Elder and her daughter», HThR, XXXVI, $147 \mathrm{ss}$.

SLATER, R.A., 1967: «Diva Faustina», the Empress of Antoninus Pius, North. Americ. Journ. 6, 3 ss.

\section{Hispania}

ÁLVAREZ BURGOS, F., 1982: Catálogo General de la Moneda Hispánica, Madrid, 236-237.

BELTRÁN LLORIS, F., 1975: «Las representaciones de Hispania en las monedas romanas», Miscelanea Arqueológica, Zaragoza, 173-250.

BLÁZQUEZ, J.M., 1983: «Una ciudad Bética de agricultores: la Itálica de Hadriano», La Cittá Antica come fatto di cultura. Atti del convegno di Como e Bellagio 16/19 giugno 1979, 93-104.

BLÁZQUEZ, J.M., 1975: «Hispania desde el año 138 al 235», Hispania, 35, 67.
BLÁZQUEZ, J.M., 1982: «La Hispania de Hadriano», Homenaje a Conchita Fernández Chicarro, Madrid, 301-317.

CASTILLO, C., 1965: Prosopographia Baetica, Pamplona.

CASTILLO, C., 1975: «Städte und Personen der Baetica», ANRW, 2.3. Nueva York-Berlín, 1975, 633 ss

DELGADO, A., 1876: Nuevo método de clasificación de las medallas autónomas de España, Sevilla, láms. CXCI-CXCIII.

ETTIENE, R. , 1996: «Les empereurs romains d'Espagne», Colloques internationaux du centre National de la recherche scientifique, París.

ETTIENE, R., 1958: Le Culte Imperial dans la Péninsule Ibérique. D'Auguste a Diocletien, París, 463-464

FRIEDLANDER, J., 1875: «Raisemünze des Hadrians (Adventvs Avg Hispaniae)», $Z N, 113$ ss.

HEISS, A., 1870: Atlas of the Ancient coins of Spain, París, reed. Chicago, 1976, pl. LXVIII.

HILL, A., 1931: Notes of the ancient coinage of Hispania Citerior, New York.

MENÉNDEZ PIDAL, R., 1955: Historia de España II: España Romana, Madrid.

NIERHAUS, R., 1965 «Zum wirtschaftlichen Aufschwung der Baetica zur Zeit Traianus und Hadrianus», Les empereurs romains d'Espagne, París, 181 ss.

NIERHAUS, E., 1966: 'Hadrians Verhältnis zu Italia», Corolla Memoriae Erich Swoboda dedicata, 121 ss.

SANCHEZ LEÓN, M.L., 1978: Economía de la España Meridional durante la dinastía de los Antoninos, Salamanca

THOUVENOT, R., 1940: Essai sur la Province romaine de Bétique, París.

\section{Vallum Hadriani}

ASKEW, G., 1951: The coinage of Roman Britain, London.

AUSTEN, P.S.-BREEZE, D.J., 1979: «A new inscription from Chesters on Hadrian», Arch Ae. VII, 115-126.

BIRLEY, A.R., 1973: Hadrian's wall: An illustrated guide London, 1973.

BREEZE, D.J.-DOBSON, B., 1972: «Hadrian's wall: Some problems», Britannia 3, 182-208.

BRUCE, J.C., 1933: The Handbook to the Roman Wall, London.

BRUN, R., 1952: The government of the Roman Empire from Augustus to the Antonines, London, 1952

CASEY, P.J., 1984: Roman coinage in Britain, London.

COLLINGWOOD, R.G., 1925-1926: «Hadrian's Wall», Hist. X, 193-202.

COLLINGWOOD, R.G.,-MYRES, I.N.L., 1937: Roman Britain and the English settlements London.

DRUMMOD, ST.K., 1981: The Roman army as a frontier institution in the first and second centuries A.D. University of Kansas.

DYSON, S.L., 1985: The creation of the Roman frontier London.

FORDE, J.-JOHNSTON, L., 1978: Hadrian's Wall, London, 1978.

GOODCHILD, R.G., 1941: «Romano-British disc-brooches derived from Hadrianic coin types», Ant J, 1-8.

HARRIS, E.-HARRIS, J.R., 1965: The Oriental cults in Roman Britain, Leiden.

HEITLAND, W.E., 1921: Agricola Cambridge.

HIND, J.G.F., 1977: «The genounian part of Britain», Britannia, VIII, 229-234.

HOLDER, P.A., 1982: The Roman Army in Britain, London.

HOME, G., 1948: Roman London A.n. 43-457 London.

JONES, B., 1976: Hadrian's wall from the air London, 1976. 
LUTTWAK, E.N., 1975: Force and diplomacy in Roman Strategies of Imperial security, The Johns Hopkins University.

MOTHERSOLE, J., 1922: Hadrian's Wall, London.

MOWAT, R., 1904.» Monnaies d'Hadrian relatives au débarquement de son armée en Bretagne», ArchAel, 138 ss

RICHMOND, I.A., 1959: «The Roman Frontier Land», Hist. XLIV, 13 ss.

RICHMOND, I.A., 1950: «Hadrian's Wall 1939-1949», JRS, 43-57.

RICHMOND, I.A., 1947: Handbook of the Roman Wall London, 1947.

ROSSI, L., 1966: «An hypothesis concerning the auxiliary signa of the Romano-British army under the Antonines» Ncir., 240 ss.

SALWAY, P., 1967: The Frontier people of Roman Britain, London.

SHOTTER, D C.A., 1980 «The Roman occupation of northwest England. The coin evidence», TCWA, XXX, 1.

SIMPSON, F.G.-RICHMOND, I.A., 1935: «The turf Wall of Hadrian», JRS, 1-18.

STEVENS, C.F., 1955: «Hadrian and Hadrian's Wall», Latomus, XIV, 3, 384-403.

STEVENSON, G.H., 1949: Roman provincial administration till the Age of the Antonines, Oxford

TODD, M., 1981: Roman Britain 55 B.C.-A.D. 400, London.

TOYNBEE, J.M.C., 1964: Art in Britain under the Romans, Oxford.

TOYNBEE, J.M.C., 1924: «Britannia of Roman coins of the second century A.D.», JRS, XIV, 142-143.

WILSON, D.R., 1979: «Roman Britain 55 B.C.-A.D. 409» BritishHistory llustrated, VI, I ss.

\section{Vallum Antonini}

KEPPIE, L.J.F., 1975-1976: «Some rescue excavation on the line of the Antonine Wall, PSAS 107, 61-68..

ROBERTSON, A.S., 1949: «The Antonine Wall», Congress of Roman Frontier Studies 99 ss.

ROBERTSON, A.S., 1960: The Antonine Wall, London,

STEER, K.A., 1965: «The Antonine Wall: A reconsideration», Studien zu den Militärgrenzen Roms, 35-41

VON HAGEN, V.W., 1973: Los Caminos que conducian a Roma, Barcelona.

\section{Limes del Rhin-Danubio.}

ALFÖLDI, A., 1949: «The moral barrier on Rhine and Danube», Congress of Roman Frontier Studies, 1-16.

AMIT, M., 1965: «Les moyens de communication et la défence de l'Empire Romain», La Parola del Passato, XX, 207-222.

BAATZ, D., 1975: Der römische Limes. Archäologische Ausflüge zwischen Rhein und Donau, Berlín.

BECHERT, T., 1982: Römisches Germanien zwischen Rhein und Maas. Die Provinz Germania Inferior, Zurich.

BECK, W., PLANCK, D., 1980: Der Limes in Sudwestdeutschland. Stuttgart.

BOGAERS, J.E.-RUEGER, C.B., 1974: Der Niedergermanische Limes. Materialen zu seiner Geschichte, Colonia.

BROGAN, O., 1935: «The Roman Limes in Germany», AJ XCII, (1935) 1-41.

CAGNAT, R., 1901: «Les frontières militaires de 1'Empire Romain», $J S, 29-40$.

DEINASS, K., 1982: Der Limes: römische Grenzwall in, Westerwald und Taunus; die Dokumentation der Rhein-zeitung, Berlín.
DREXEL, F., 1968: «Die Grenztruppen des obergermanischen Limes im 2. Jahrhundert», Germania, XLVI.

FORNI, G., 1953: Il reclutamiento delle legioni da Augusto a Diocleziano, Milán-Roma

GUTENBRUNNER, S., 1941: «Uber Decumates Agri als Zehtland aufgefasst», Klio, 357-363.

KAHRSTEDT, U., 1949: «The Roman frontier on the lower Rhine in the early imperial Period», Congress of Roman Frontier Studies, 41-54.

KRAFT, K., 1951: Zur Rekrutierung der Alen und Kohorten an Rhein un Donau, Berna.

LOT, F., 1946: Les invasions germaniques: La penetration mutuelle du monde barbare et du monde romain, París.

NOVOTNY, E., 1925: «Vom Donau-Limes». AA WW. LXII, 89-142.

OELMANN, F., 1949: «The Rhine Limes in Late Roman Times», Congress of Roman Frontier Studies, 81-99.

PARKER, H.D.M., 1928: The Roman Legions, Oxford-London, 291 ss.

PETRIKOVITS, H.V., 1955: «Beobachtungen am niedergermanischen Limes seitdem Weltkrieg», SJ, XIV, 7 ss.

PETRIKOVITS, H.V., 1960: Das Römische Rheinland Archäologische Forschungen Zeit, Colonia-Opladen.

RITTERLING, E., 1925: Rheinische Legionare an der unteren Donau in Germania, Berlín.

SCHLEIERMACHER, W., 1959: Der romische Limes in Deutschland, Berlín.

SCHLEIERMACHER, W., 1943-1950: «Der obergermanische Limes und spätrömische Wehranlagen am Rheim», $B R G K$, XXXIII, 136 ss.

SCHLEIERMACHER, W., 1954: «Beobachtungen am obergermanischen und raetischen Limes», SJ, XIII, 71 ss.

SCHLEIERMACHER, W., 1953: «Römische Archaologie am Rhein 1940 bis $1950 »$, Hist. II, 94-110.

SCHONBERGER, H., 1955: The Roman camp at the Saalburg, Hamburg.

WEBSTER, G., 1969: The Roman Imperial Army of the first and second centuries, London, 1969.

\section{Dacia}

DAICOVICIU, H., 1965: Dacii, Bucarest.

FORNI, G., 1960: «Dacia Romana tributim descripta», Omagiu lui Daicoviciu, 225-232.

\section{Provincias del Próximo Oriente}

ASDURIAN, J., 1912: Le relazioni politiche fra l'Armenia e Roma dal 190 a.C. fino al 438 d.C., Venecia.

BARBIERINI, G,, 1938: «L'amministrazione delle provincie Ponto-Bitinia e Licia-Panfilia nel II sec. d.C.», Riv. Fil., Roma, 365 ss.

BOWERSOCK, G.W., 1976: «Limes Arabicus», HSPH, LXXX, 219-229.

BRÜNNOW, RDOMASZEWSKI, W.VON., 1904-1909: Die Provincia Arabia, Estrasburg.

CHAPOT, V., 1904: La province romaine proconsulaire d'Asie, París.

DOWNEY, G., 1961: A History of Antioch in Syria from Seleucus to the Arab conquest, Princenton.

FELLETI-MAS, B.M., 1950: Siria, Palestina, Arabia settentrionale nel periodo romano. 
FRECH, D.H., 1980: «The Roman road-system of Asia Minor», ANRW, II, 7, 2, 698-729.

GRAY, W.D., 1923: «New light from Aegypt on the early reign of Hadrian», $A J P h, \mathrm{XL}, 14$ ss.

JONES, A.H.M., 1937: Cities of the Eastern Roman provinces, Oxford.

LEVICK, B.M., 1977: Roman colonies in Southern Asia Minor, Oxford

MACRO, A.D., 1980: «The Cities of Asia Minor under the Roman Imperium», $A N R W$, II, 7, 2, 658-697.

MAGIE, D., 1950: Roman Rule in Asia Minor, Princeton.

NADEL, B., 1982: «Aspects of Emperor Hadrian's policy in the norther Black Sea area», RSA, 12, 175-216.

MOUTERDE, R.-POIDEBARD, A., 1945: Le Limes de ChalcisOrganisation de la steppe en Haute Syrie romaine, París.

MUNRO, L.A.R., 1901: «Roads in Pontus, Bithynia and the Bosphorius», JHS, XXI, 52 ss.

PARKER, S. TH, 1979: The Historical Development of the Limes Arabicus, University of California, Los Angeles.

POIDEBARD, A., 1934: La Trace de Rome dans le desert de Syrie, París.

ROSTOVTZEFF, M., 1918: «Pontus, Bithynia and the Bosphorius», ABSA, XXII, I ss.

SOLCH, J., 1925: «Bithynische Städte im Altertum», Klio, XIX, 165 ss.

TALIP, S., 1938: La strade romane in Anatolia, Espoleto.

VITUCCI, G., 1953: Il regno di Bitinia, Roma.

Limes de Raetia, Pannonia, Mesia y Thracia y las defensas de otras provincias europeas para esta época.

BARADEZ, J.L., 1965: «L'Enceite de Tipasa: base d'operations des troupes venues de Pannonie sous Antonin le Pieux», Quintus Congressus Internationalis Limitis Romani Studiosorum, 75-82.

DRINKWATER, J.F., 1984: Roman Gaul: the three provinces, 58 B.C.-A.D. 260, London, 1984.

GARBASCH, J., 1965: Die Norish-Pannonische Frauentracht im I Jahrhundert, München.

GEROV, B., 1961: «Römische Burgerrechtsverleihung und Kolonisation in Thrakien von Trajan», Stud. Clas. III, 107 ss.

HATT, J.J., 1959: Histoire de la Gaule Romaine, París.
JULLIAN C., 1913-1926: Histoire de la Gaule, París.

MILLAR F., 1966: «Emperor, the Senate and the Provinces», JRS, LVI, 156-166.

MIHAILOV, G., 1961: «La fortification de la Thrace par Antonin le Pieux el Marc Aurèle», Stud. Urb. 35, 42 ss.

MOMMSEN, TH., 1968: The Provinces of the Roman Empire. The European provinces. Ed. T.R.S. Broughton, The History of Rome, V, 8. University of Chicago Press.

MOSCY, A., 1959: «Untersuchungen zur Geschichte der römische Provinz Moesia Superior», AArchHung, X1, 282 ss.

MOSCY, A., 1962: «Pannonia», RE Supl. 9, 516-517.

MOSCY, A., 1974: La Pannonie sous le Haut Empire, Budapest.

MOSCY, A., 1976: «Pannonia and Upper Moesia», Ant J., LVI, 286-288.

POLASCHEK, E., 1937: «Noricum», RE, XIX, 971-1048.

STEVENSON, G.H., 1939: Roman provincial administration, London.

SYME, R., 1965: «Governors of Pannonia Inferior», Hist. XIV, 342 ss.

THOMAS, E.B., 1964: Römische Villen in Pannonien, Budapest.

WAGNER, F., 1951-1952: «Das Ende der römischen Herrschaft in Raetien», Bayerische Vorgeschichtsblatter, Munchen, XVIIIXIX, 26 ss.

WIESNER, J., 1963: Die Thraker, Stuttgart.

\section{Sobre Elio Aristides y El Elogio o Encomio de Roma.}

BLEICKEN, J., 1966-1967: «Der Preis des Aelius Aristides auf das römische Weltreich», NAWG, 225 ss.

BOULANGER, A., 1922: «Cronologie de la vie du rhéteur Aristide», $R$. $P h$, XLVI, 26 ss.

BOULANGER, A., 1923: «Aelius et la sophistique dans la province d'Asie du II ème sièle de notre ére», Bibl. des Ec., 126.

MESK, J., 1909: «Der Aufbau der XXVI Rede des Aelius Arístides》 Jahresh. über das K.K. Franz Joseph Realgymnasium, Wien, 5.

OLIVER, J.H., 1953: «The ruling powers. A Study of the Roman Empire in the second century after Christ through the Roman Oration of Aelius Aristides», $\mathrm{TaPhA}, 43,4$, Filadelfia.

PAVAN, M., 1962: «Sul significato storico dell «Encomio di Roman» di Elio Arístide», $P P, 17,81$ ss. 